\title{
CHEMOMETRICS ASSISTED SPECTROPHOTOMETRIC METHOD FOR SIMULTANEOUS DETERMINATION OF CERTAIN FLUOROQUINOLONES AND THEIR DECARBOXYLATED DEGRADANTS
}

\author{
A. I. Mohamed ${ }^{1 *}$, N. A. El-Koussi ${ }^{2}$ and N. A. Mohamed ${ }^{1}$ \\ ${ }^{1}$ Department of Pharmaceutical Analytical Chemistry and ${ }^{2}$ Department of Pharmaceutical \\ Medicinal Chemistry, Faculty of Pharmacy, Assiut University, Assiut, 71526 Egypt
}

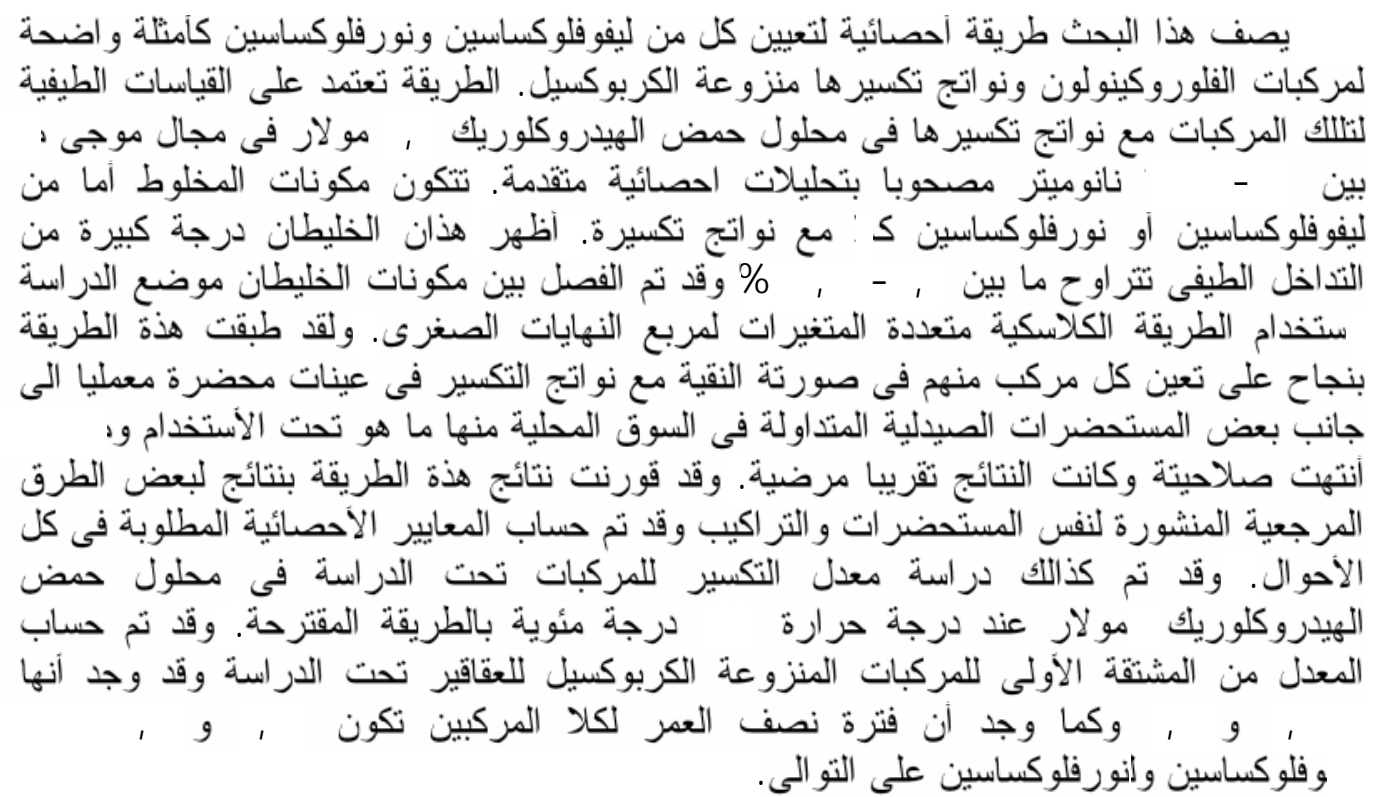

Simple multivariate spectrophotometric procedure for simultaneous determination of levofloxacin and norfloxacin as representative examples of fluoroquinolones and their decarboxylated degradation products is described. The method is based on the spectrophotometric measurements of the studied drugs and their degradants in $0.1 \mathrm{M}$ hydrochloric acid solutions in the general range of 200-370 $\mathrm{nm}$ together with multivariate calibration analysis. The components of mixtures composed of either levofloxacin or norfloxacin and the corresponding degradant. show a considerable degree of spectral overlapping (85.1-87.4\%). Resolution of the binary mixtures under investigation has been accomplished mainly by using classical least squares (CLS) analysis. The method is applied successfully for determination of each drug in pure form, laboratory prepared degraded samples and in expired commercial dosage forms and good recoveries were obtained. Results were compared to those obtained by reported procedures for the same combinations and the required statistical parameters were calculated. The degradation rates for the studied drugs at $150^{\circ}$ in $2 \mathrm{M} \mathrm{HCl}$ were also studied using the proposed procedure. The calculated first order rate constants for the decarboxylation of the studied drugs were found 0.109 and 0.082 hour ${ }^{-1}$ and the $t_{1 / 2}$ were 6.32 and 8.50 hours for levofloxacin and norfloxacin respectively.

\section{INTRODUCTION}

Levofloxacin (LF) and norfloxacin (NF) are fluoroquinolone derivatives that are used widely as antibacterial agents. ${ }^{1-5}$ Several methods have been reported for determination of both drugs including chromatography, ${ }^{6-11}$ capillary zone electrophoresis, ${ }^{12}$ 
spectrophotometry, ${ }^{13-15}$ spectrofluorometry, ${ }^{16-18}$ NMR spectroscopy ${ }^{19}$ and electrochemical methods. ${ }^{20-22}$ The USP (24) and BP (1998) recommended non-aqueous titrimetry with potentiometric detection of end point for the pure compounds and HPLC procedures for ophthalmic solutions and tablets. ${ }^{23,24}$ Few attempts were made to quantify both drugs in presence of some of their degradation products especially the decarboxylated degradation products. $^{25,26}$ The later products may be resulted during heating or storage in acidic solutions. Moreover, the decarboxylated degradants had been identified as insoluble impurities in some fluoroquinolone injections and as related impurities in the powder of some others. ${ }^{13,27}$ The decarboxylated degradation products are of particular significance because of the urgent importance of the carboxylic group for the biological activity of these type of drugs. ${ }^{3,5}$

The most used technique for simultaneous determination of fluoroquinolons and their degradation products or metabolites is HPLC. In order to develop simple method for pharmaceutical analysis, we have been exploring the use of chemometrics-enhanced spectrophotometry as suitable techniques for the analysis of active principles in different pharmaceutical forms. This is due to the simplicity and sensitivity of spectroscopic methods, and to speed of the determination, since preliminary separation steps are avoided. The required selectivity is provided by chemometrics. These characteristics make this method appealing for routine quality control programs, where they may be faster and of lower cost as compared to HPLC.

Multivariate calibration methods applied to spectral data are being increasingly used for pharmaceutical analysis. ${ }^{28-35}$ Classical least squares (CLS) analysis is one of the simplest multivariate methods that can be performed with easily accessible statistical software. In the present work we discuss the possibility of simultaneous determination of either LF or NF as representative examples of the commercial fluoroquinolones in presence of their decarboxylated degradation products by a simple, rapid and precise procedure, and subsequent application of the method to the analysis of laboratory prepared binary mixtures, laboratory degraded drug samples and some used and expired commercial formulations. The method is based on the direct spectrophotometric measurements in the general range of 200-370 $\mathrm{nm}$ together with multivariate calibration analysis. The obtained results were also compared to those obtained by some reported procedures for the same samples and combinations and the required statistical parameters were calculated. In addition, the accelerated thermal degradation at $150^{\circ}$ of both drugs in strong acid solution ( $2 \mathrm{M}$ $\mathrm{HCl}$ ) was monitored over 36 hours and the drug degradation rates were determined.<smiles></smiles>

Levofloxacin

Norfloxacin

Decarboxylation prosluct 


\section{EXPERIMENTAL}

\section{Apparatus}

Spectrophotometric measurements were carried out on a computerized UV-1601 PC, UV-visible Shimadzu spectrophotometer (Tokyo-Japan), using $1.00 \mathrm{~cm}$ quartz cells. The obtained spectral data were saved in PC Shimadzu program and the subsequent statistical manipulation was performed by transferring the spectral data to Microsoft excel 2000 program and processing them with the standard curve fit package and matrix calculations.

\section{Chemicals}

Pharmaceutical grade LF supplied by Sinochem, Hebei, China and NF by Egyptian International Pharmaceutical Industries Company (EIPICO), Cairo, Egypt were used as working standards. Their purity and compliance with the pharmacopoial requirements were checked by some reported ${ }^{13}$ and official procedures ${ }^{23,24}$ and were found to be 100.2 and 99.5 for LF and NF respectively. All working reagents and solvents used throughout this work were spectroscopic and analytical grade.

\section{Dosage forms}

Investigated formulations are obtained from the local market and include:

1- Norbactin Tablets (Chemical Industries Development, CID, Giza, Egypt); Labeled to contain $800 \mathrm{mg} \mathrm{NF}$, Batches number 106 and 107 that expired at 6, 2003 and 4, 2004 respectively.

2- Spectrama Tablets (Amoun Pharmaceutical Co, Cairo, Egypt); Labeled to contain 400 mg NF, Batch number 743, expired at 2, 2003.

3- Tavanic Tablets (Hoechst Marion RousselGermany); Labeled to contain $256.23 \mathrm{mg}$ of LF hemihydrate equivalent to $250 \mathrm{mg} \mathrm{LF}$, Batch number 12E03, expired at 9, 2004.

4- Opto Q3 drops (CID, Giza, Egypt); Labeled to contain $3 \mathrm{mg} \mathrm{NF}$ for each $1 \mathrm{ml}$, Batch number 401106, expired at 4, 2003.

\section{Preparation of the completely decarboxy- lated $\mathrm{LF}$ and $\mathrm{NF}$}

Accurately weigh about $0.2 \mathrm{~g}$ portion of either pure LF or NF powder and reflux with
$40 \mathrm{ml}$ of $2 \mathrm{M} \mathrm{HCl}$ solution on a heating mantle at $150^{\circ}$ for 40 hours while protecting the solution from light. Cool and adjust to $\mathrm{pH}$ 7-8 with $2 \mathrm{M} \mathrm{KOH}$ solution. Evaporate to dryness under vacuum. Extract the residue three times each with $40 \mathrm{ml}$ of ethanol, filter and evaporate again under vacuum to give the solid product. The obtained products are analyzed for their purity and the presence of the intact and decarboxylated drugs by some reported procedures. ${ }^{13,23-24}$ The results revealed the presence of $99.5 \%$ and $98.5 \%$ of decarboxylated LF and NF respectively in the prepared samples. The prepared solids are used as completely decarboxylated samples and the required mathematical corrections were performed for the obtained results.

\section{Preparation of degraded levofloxacin and norfloxacin samples}

Repeat the same procedure (as above) for preparation of decarboxylated derivatives to prepare the different degraded samples by refluxing equal portions of either $\mathrm{LF}$ or $\mathrm{NF}$ at $150^{\circ}$ for $4,8,12,16,20,24,28,32$ and 36 hours respectively. The prepared samples were evaluated with both reported and proposed procedures.

\section{Preparation of standard and degraded solutions}

Dissolve an accurately weighed amount $(25 \mathrm{mg})$ of either LF, NF or any of their prepared degraded samples in $0.1 \mathrm{M} \mathrm{HCl}$ and dilute quantitatively with the same solution to obtain the appropriate dilution for each drug according to its linear calibration range.

\section{Preparation of Tablet samples}

Weigh 20 tablets and finely powder. Transfer accurately weighed amount of the powder equivalent to one tablet to $100 \mathrm{ml}$ volumetric flask and dilute to about $80 \mathrm{ml}$ with $0.1 \mathrm{M} \mathrm{HCl}$. Sonicate or shake the mixture well for about 15 minutes, dilute to the mark with the same solution and filter. Discard the first portion of filtrate. Use clear solution obtained as stock sample solution. Dilute a suitable aliquot of the stock solution quantitatively with $0.1 \mathrm{M} \mathrm{HCl}$ to obtain the suitable working sample solution for $\mathrm{UV}$-measurements. 
Preparation of ophthalmic solutions samples

Transfer an accurately measured volume of the ophthalmic solution $(5 \mathrm{ml})$ to $100 \mathrm{ml}$ volumetric flask and dilute quantitatively with $0.1 \mathrm{M} \mathrm{HCl}$, shake well and use this solution as stock solution. Dilute a suitable aliquot of the stock solution quantitatively with $0.1 \mathrm{M} \mathrm{HCl}$ to obtain the suitable working sample solution for UV-measurements.

\section{Standard solutions for multivariate calibration}

In order to obtain the calibration matrix for applying CLS analysis, ten solutions of each of the pure components LF, decarboxylated LF, NF and decarboxylated NF were prepared with concentrations in the range 2.5-17.5, 2.5-25, 2.5-17.5 and 2.5-25 $\mu \mathrm{g} . \mathrm{ml}^{-1}$ respectively. These ranges were previously verified to obey Beer's law for each of the studied compounds in the suitable reagent solution. The absorption data in the range of 200-370 nm (digitized every $1.0 \mathrm{~nm}$ ) were subjected to least squares analysis in order to obtain the calibration K matrix (see below). Laboratory prepared mixtures were then prepared by mixing known amounts of either LF with its decarboxylated product or NF with its decarboxylated product in different varied proportions in $0.1 \mathrm{M} \mathrm{HCl}$ (Table 2), in order to verify the precision of the method for analysis of similar mixtures and matching the purchased tablets or prepared samples with those having comparable concentrations.

\section{RESULTS AND DISCUSSION}

The UV spectra of the intact LF and NF showed a small bathochromic shift (From 282 to $294 \mathrm{~nm}$ for LF and from 265 to $278 \mathrm{~nm}$ for NF) accompanied by a simultaneous hyperchromic effect in $0.1 \mathrm{M} \mathrm{HCl}$ solutions from those of their corresponding decarboxylated degradants (Figures 1 and 2). These small shifts in absorption spectra could be the reason for the use of the multivariate analysis for the determination of the intact drugs as well as their degradation products. As can be seen, a considerable degree of spectral overlapping occurs in the region from 200 to $370 \mathrm{~nm}$. The degree of spectral overlapping can be conveniently given by $\left(D_{i}\right)^{0.5}$. Where $D_{i}$ is the magnitude of dependency, which can be calculated for a two components mixture from equation (1).

$$
\mathrm{Di}=\frac{\left(\sum \mathrm{K}_{1} \mathrm{~K}_{2}^{\mathrm{t}}\right)^{2}}{\sum \mathrm{K}_{1} \mathrm{~K}_{1}^{\mathrm{t}} \cdot \sum \mathrm{K}_{2} \mathrm{~K}_{2}^{\mathrm{t}}}
$$

Where $\mathrm{K}_{1}$ and $\mathrm{K}_{2}$ are the $\boldsymbol{l} \boldsymbol{x} \boldsymbol{n}$ matrices of regression coefficients for the drug and its decarboxylated form respectively. In case of the presently studied compounds and their degradation products, the spectra shown in Figures 1-2 lead to $\mathrm{Di}=0.764$, implying a $87.4 \%$ of spectral overlap for the first mixture (LF and Decarboxylated LF) and Di $=0.723$, implying a $85.1 \%$ of spectral overlap for the second mixture (NF and Decarboxylated NF) respectively.

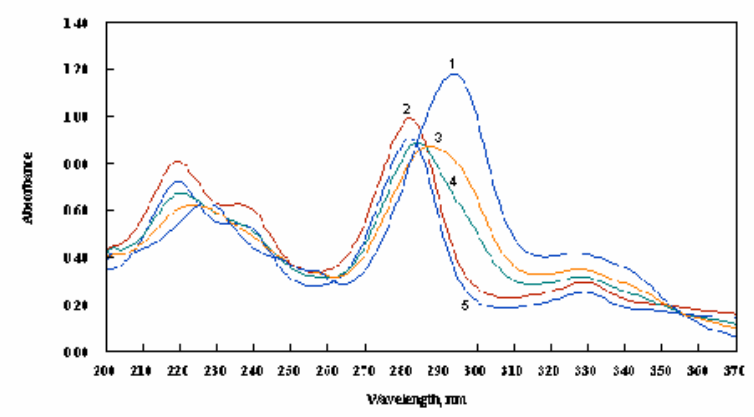

Fig. 1: The UV-absorption spectra of intact LF(1), decarboxylated LF (2) and three degaraded samples of $\mathrm{LF}$ by reflux at $150^{\circ}$ in $2 \mathrm{M} \mathrm{HCl}$ for 8(3), 16(4) and 24(5) hours respectively.

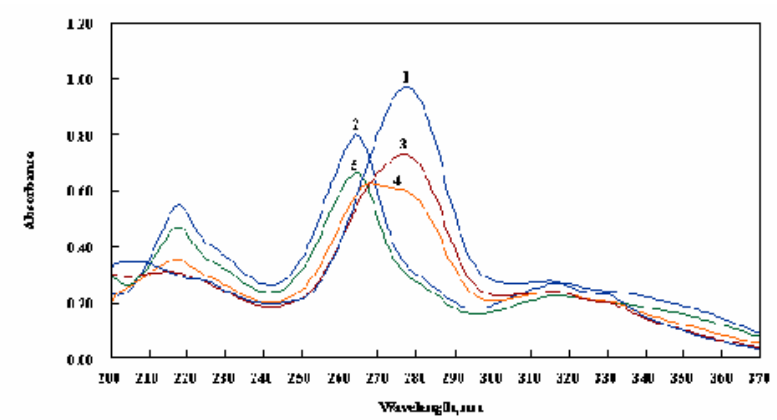

Fig. 2: The UV-absorption spectra of intact NF(1), decarboxylated NF (2) and three degaraded samples of $\mathrm{NF}$ by reflux at $150^{\circ}$ in $2 \mathrm{M}$ $\mathrm{HCl}$ for 8(3), 16(4) and 24(5) hours respectively. 
Derivative spectrophotometric techniques can not precisely resolved these mixtures due to the high degree of spectral overlapping. Fullspectrum methods usually provide significant improvement in precision over methods restricted to a small number of wavelengths. A convenient method for resolving the mixtures, which can in principle be applied to the present case, as we mentioned above, is the classical least squares (CLS). It should certainly be preferred here because the selection of variables is so simple, the regression coefficients for different selected collinear wavelengths performs well, both in calibration and in prediction phases, the model possess linearity between response (absorbance) and concentration and the prediction is performed within the calibration domain.
Table 1 showed the predicted amounts (\% \pm RE) of the studied drugs and their decarboxylated degradants as given by the least squares regression analysis of the spectral data that obtained experimentally in the range from 200 to $370 \mathrm{~nm}$.

To assess the efficiency of the suggested procedure as a stability indicating assay, several synthetic mixtures of each compound and its corresponding decarboxylated form prepared in continuously varied proportions were subjected to the analysis by the proposed method. It is clear from the results (Table 2), that the method is applicable for the selective assay of the intact drugs in presence of their degradation products and vice versa. The recoveries in all cases were satisfactory and the relative deviations between the estimated and

Table 1: Predicted concentrations of LF, decarboxylated LF, NF and decarboxylated NF in $0.1 \mathrm{M}$ hydrochloric acid \pm relative errors as calculated by CLS calibration method.

\begin{tabular}{||c|c|c|c|c|c|c|c|c||}
\hline \multirow{2}{*}{$\begin{array}{c}\text { Taken } \\
\begin{array}{c}\text { Conc. } \\
\left(\mu \mathrm{gg} \cdot \mathrm{ml}^{-1}\right)\end{array}\end{array}$} & $\begin{array}{c}\text { Found } \\
\left(\mu \mathrm{g} \cdot \mathrm{ml}^{-1}\right)\end{array}$ & $\% \pm \mathrm{RE}^{*}$ & $\begin{array}{c}\text { Found } \\
\left(\mu \mathrm{g} \cdot \mathrm{ml}^{-1}\right)\end{array}$ & $\% \pm \mathrm{RE}^{*}$ & $\begin{array}{c}\text { Found } \\
\left(\mu \mathrm{g} \cdot \mathrm{ml}^{-1}\right)\end{array}$ & $\% \pm \mathrm{RE}^{*}$ & $\begin{array}{c}\text { Found } \\
\left(\mu \mathrm{g} \cdot \mathrm{ml}^{-1}\right)\end{array}$ & $\% \pm \mathrm{RE}^{*}$ \\
\hline 2.5 & 2.499 & $99.96 \pm 1.33$ & 2.482 & $99.28 \pm 1.87$ & 2.461 & $98.44 \pm 1.98$ & 2.517 & $100.68 \pm 1.76$ \\
\hline 5.0 & 5.071 & $101.42 \pm 0.81$ & 4.980 & $99.60 \pm 1.23$ & 4.865 & $97.30 \pm 1.92$ & 4.941 & $98.82 \pm 1.88$ \\
\hline 7.5 & 7.350 & $98.00 \pm 1.03$ & 7.420 & $98.93 \pm 1.45$ & 7.451 & $99.35 \pm 1.34$ & 7.384 & $98.45 \pm 1.68$ \\
\hline 10.0 & 10.082 & $100.82 \pm 1.11$ & 9.897 & $98.97 \pm 0.76$ & 10.062 & $100.62 \pm 1.16$ & 9.857 & $98.57 \pm 1.22$ \\
\hline 12.5 & 12.689 & $101.51 \pm 0.44$ & 12.440 & $99.52 \pm 1.01$ & 12.672 & $101.38 \pm 1.45$ & 12.330 & $98.64 \pm 1.98$ \\
\hline 17.5 & 17.33 & $99.03 \pm 2.08$ & 17.653 & $100.87 \pm 0.88$ & 17.628 & $100.73 \pm 0.99$ & 17.677 & $101.01 \pm 0.87$ \\
\hline 25.0 & $\mathrm{ND}$ & $\mathrm{ND}$ & 25.333 & $101.32 \pm 1.87$ & $\mathrm{ND}$ & $\mathrm{ND}$ & 25.054 & $100.22 \pm 0.65$ \\
\hline
\end{tabular}

* Relative errors as calculated from the CLS model.

ND Not determined.

Table 2: Results obtained by applying CLS analysis to synthetic mixtures of LF and its decarboxylated product (DLF) and NF and its decarboxylated product (DNF) in $0.1 \mathrm{M}$ hydrochloric acid solutions.

\begin{tabular}{|c|c|c|c|c|c|c|c|c|c|}
\hline Compd. & $\begin{array}{c}\text { Actual } \\
\left(\mu \mathrm{g} . \mathrm{ml}^{-1}\right)\end{array}$ & $\begin{array}{c}\text { Found } \\
\left(\mu \mathrm{g} . \mathrm{ml}^{-1}\right)\end{array}$ & $\begin{array}{c}\text { Recovery } \\
(\%)\end{array}$ & $\begin{array}{c}\text { RRMSE* } \\
(\%)\end{array}$ & Compd. & $\begin{array}{c}\text { Actual } \\
\left(\mu \mathrm{g} . \mathrm{ml}^{-1}\right)\end{array}$ & $\begin{array}{c}\text { Found } \\
\left(\mu \mathrm{g} . \mathrm{ml}^{-1}\right)\end{array}$ & $\begin{array}{c}\text { Recovery } \\
(\%)\end{array}$ & $\begin{array}{c}\text { RRMSE* } \\
(\%)\end{array}$ \\
\hline LF & 5.00 & 5.08 & 101.6 & 1.7 & $\mathrm{NF}$ & 5.00 & 5.101 & 102.02 & 2.0 \\
\hline DLF & 20.00 & 19.60 & 97.98 & 2.0 & DNF & 20.00 & 20.22 & 101.10 & 1.1 \\
\hline LF & 7.50 & 7.44 & 99.20 & 0.8 & NF & 7.50 & 7.636 & 101.81 & 1.8 \\
\hline DLF & 17.50 & 17.41 & 99.46 & 0.5 & DNF & 17.50 & 17.30 & 98.86 & 1.1 \\
\hline LF & 10.00 & 9.79 & 97.90 & 2.1 & NF & 10.00 & 10.19 & 101.90 & 1.9 \\
\hline DLF & 15.00 & 14.88 & 99.23 & 0.8 & DNF & 15.00 & 14.91 & 99.40 & 0.6 \\
\hline LF & 12.50 & 12.56 & 100.48 & 0.5 & NF & 12.50 & 12.61 & 100.88 & 0.9 \\
\hline DLF & 12.50 & 12.66 & 101.26 & 1.3 & DNF & 12.50 & 12.59 & 100.72 & 0.7 \\
\hline LF & 15.00 & 14.81 & 98.73 & 1.3 & NF & 15.00 & 15.28 & 101.86 & 1.9 \\
\hline DLF & 10.00 & 10.13 & 101.30 & 1.3 & DNF & 10.00 & 9.953 & 99.53 & 0.5 \\
\hline LF & 17.50 & 17.40 & 99.43 & 0.6 & NF & 17.50 & 17.69 & 101.09 & 1.1 \\
\hline DLF & 17.5 & 17.61 & 100.63 & 0.6 & DNF & 17.50 & 7.572 & 100.96 & 1.0 \\
\hline LF & 20.00 & 19.59 & 97.95 & 2.0 & NF & 20.00 & 20.13 & 100.65 & 0.7 \\
\hline DLF & 5.00 & 5.056 & 101.12 & 1.1 & DNF & 5.00 & 4.900 & 98.00 & 2.0 \\
\hline
\end{tabular}

$* \operatorname{RRMSE}(\%)=100 \times\left[\Sigma\left(\mathrm{C}_{\mathrm{i}}-\hat{\mathrm{C}}_{\mathrm{i}}\right)^{2} / \sum \mathrm{C}_{\mathrm{i}}^{2}\right]^{1 / 2}$,

Where $\hat{C}_{i}$ and $C_{i}$ are predicted and real concentrations respectively, for the compound in the standard and sample solutions. 
true concentrations expressed by the relative root mean squared error (RRMSE) were found between 0.5 and $2.1 \%$ for both drugs and their degradation products. The results may reflect the precision of the method for the prediction of the concentrations of both mixture components upon degradation step of the intact compound to the corresponding decarboxylated-derivative.

On other hand, the proposed method is compared to some commonly reported $\operatorname{methods}^{13,15}$ with respect to their efficiency as stability indicating procedures. The results (Table 3) revealed that the proposed method is

Table 3: Results obtained by applying the proposed and some reported procedures for analysis of certain synthetic mixtures of NF in presence of its decarboxylated product (DNF).

\begin{tabular}{|c|c|c|c|c|c|}
\hline \multirow{2}{*}{ Drug } & Actual & \multicolumn{5}{|c|}{ Found (\%) } \\
\cline { 3 - 6 } & $\left(\mu \mathrm{g} \cdot \mathrm{ml}^{-1}\right)$ & Proposed & $(1)^{*}$ & $(2)^{* *}$ & $(3)^{+}$ \\
\hline NF & 5.00 & 102.0 & 154.8 & 136.3 & 188.7 \\
\hline DNF & 20.00 & 101.1 & --- & --- & --- \\
\hline NF & 10.00 & 101.9 & 126.2 & 116.8 & 142.1 \\
\hline DNF & 15.00 & 99.4 & --- & --- & --- \\
\hline NF & 15.00 & 101.9 & 112.0 & 103.6 & 131.3 \\
\hline DNF & 10.00 & 99.5 & --- & --- & --- \\
\hline NF & 20.00 & 100.7 & 98.5 & 102.2 & 112.0 \\
\hline DNF & 5.00 & 98.0 & --- & --- & --- \\
\hline \hline
\end{tabular}

A procedure. ${ }^{13}$

** Iron (II) chelation procedure. ${ }^{13}$

+ Second-derivative procedure. $^{15}$ much more efficient especially at high concentrations of the degradation products if compared with the others. Furthermore the proposed method is used for simultaneous determination of both the drug and its degradation products while the others used mainly for the intact drug only.

Some expired commercial dosage forms were analyzed with the proposed procedure in order to detect any decarboxylated derivatives and confirm their contents of fluoroquinolones. Moreover, the results for the analyzed dosage forms by the proposed procedure were compared to those results obtained by some reported procedures ${ }^{13}$ for the same combinations and the required statistical parameters were calculated. As shown in Table 4 , the results are in good agreement with those of reported procedures as indicated by the $\mathrm{t}$ test.

In the current investigation, the degradation rates of the studied compounds were also determined using the multivariate method discussed above. Figures 1-3 and Table 5 illustrate the results obtained for the studied compounds at different time intervals through 40 hours reflux with $2 \mathrm{M}$ hydrochloric acid at $150^{\circ}$. The first order rate constants $\left(\mathrm{k}_{\mathrm{obs}}\right.$.) for the decarboxylation of LF and NF were obtained from the slopes of the linear plots of $\log$ the predicted concentrations versus time in hours $\left(\mathrm{k}_{\mathrm{obs}}\right.$. $=-$ slope $\left.\mathrm{X} 2.303\right)$. The degradation rates of the studied drugs were found 0.109 and $0.082 \mathrm{hr}^{-1}$ for LF and NF respectively. The $\mathrm{t}_{1 / 2}$ obtained from $\mathrm{K}_{\mathrm{obs}}$ values $\left(\mathrm{t}_{1 / 2}=0.693 / \mathrm{K}_{\mathrm{obs}}\right)$ were found 6.32 and 8.50 hours for LF and NF respectively (Figure 3).

Table 4: Analysis of the studied drugs in commercial dosage forms by the CLS and reported method*.

\begin{tabular}{|c|c|c|c|c|c|c|c|}
\hline $\begin{array}{l}\text { Dosage } \\
\text { form }\end{array}$ & Drug & $\begin{array}{l}\text { Batch } \\
\text { number }\end{array}$ & $\begin{array}{l}\text { Expired } \\
\text { at }\end{array}$ & $\begin{array}{l}\text { Claimed } \\
(\mathrm{mg})\end{array}$ & $\begin{array}{cc}\text { Found }^{+} \\
(\mathrm{mg}) & (\% \pm \mathrm{SD})\end{array}$ & $\begin{array}{c}\text { D.P. }^{++} \\
(\% \pm \mathrm{SD})\end{array}$ & $\begin{array}{l}\text { Reported } \\
\text { method }^{* *} \\
(\%+\mathrm{SD})\end{array}$ \\
\hline & LF & $12 \mathrm{E} 03$ & 9,2004 & 250/tab. & $\begin{array}{cc}248.4 & 99.4 \pm 1.4 \\
\mathrm{~F}=1.47, \mathrm{t}=1.32\end{array}$ & $1.6 \pm 1.4$ & $98.1+1.7$ \\
\hline $\begin{array}{l}\text { Norbactin } \\
\text { Tablets }\end{array}$ & $\mathrm{NF}$ & 106 & 6,2003 & $800 /$ tab. & $\begin{array}{c}812.0 \quad 101.5 \pm 1.1 \\
F=1.4, t=1.71\end{array}$ & $0.1 \pm 1.9$ & $102.8 \pm 1.3$ \\
\hline $\begin{array}{l}\text { Norbactin } \\
\text { Tablets }\end{array}$ & $\mathrm{NF}$ & 107 & 4, 2004 & $800 /$ tab. & $\begin{array}{cc}793.1 & 99.1 \pm 1.8 \\
\mathrm{~F}=1.27, \mathrm{t}=1.02\end{array}$ & $1.8 \pm 1.7$ & $100.2 \pm 1.6$ \\
\hline $\begin{array}{l}\text { Spectrama } \\
\text { Tablets }\end{array}$ & $\mathrm{NF}$ & 743 & 2,2003 & 400/tab. & $\begin{array}{cc}402.4 & 101.8 \pm 1.7 \\
\mathrm{~F}=1.12, \mathrm{t}=1.36\end{array}$ & $0.6 \pm 1.8$ & $100.3 \pm 1.8$ \\
\hline $\begin{array}{l}\text { Opto Q3 } \\
\text { drops }\end{array}$ & $\mathrm{NF}$ & 401106 & 4, 2003 & $30 / 10 \mathrm{ml}$ & $\begin{array}{c}29.22 \\
\mathrm{~F}=1.27, \mathrm{t}=1.08\end{array}$ & $2.4 \pm 1.6$ & $96.3 \pm 1.4$ \\
\hline
\end{tabular}

* Average of 5 determinations \pm SD.

+ Theoretical values at $95 \%$ confidence limit are $\mathrm{t}=2.101$ and $\mathrm{F}=3.178$.

++ Decarboxylated products of the studied drugs.

** $\mathrm{F}$ (III) chelation procedure. ${ }^{13}$ 
Table 5: Predicted concentrations for equal samples $(0.1 \mathrm{~g})$ of studied drugs after reflux at $150^{\circ}$ in $2 \mathrm{M}$ hydrochloric acid for time intervals ranged from 0 to 36 hours as calculated by CLS calibration method.

\begin{tabular}{|c|c|c|c|c|c|c|c|c||}
\hline \hline \multirow{2}{*}{$\begin{array}{c}\text { Time } \\
\text { (Hours })\end{array}$} & \multicolumn{2}{|c|}{ Levofloxacin } & \multicolumn{2}{c|}{ Decarboxylated LF } & \multicolumn{2}{c|}{ Norfloxacin } & \multicolumn{2}{c|}{ Decarboxylated NF } \\
\cline { 2 - 9 } & $\left(\mu \mathrm{g} \cdot \mathrm{ml}^{-1}\right)^{*}$ & $(\%)$ & $\left(\mu \mathrm{g} \cdot \mathrm{ml}^{-1}\right)^{*}$ & $(\%)$ & $\left(\mu \mathrm{g} \cdot \mathrm{ml}^{-1}\right)^{*}$ & $(\%)$ & $\left(\mu \mathrm{g} \cdot \mathrm{ml}^{-1}\right)^{*}$ & $(\%)$ \\
\hline $\begin{array}{c}\text { Initial } \\
\text { conc. }\end{array}$ & 17.5 & 100.00 & 00.00 & 00.00 & 17.5 & 100.00 & 00.00 & 00.00 \\
\hline 0 & 17.43 & 99.60 & 0.42 & 2.40 & 17.3 & 98.86 & 0.39 & 2.23 \\
\hline 4 & 11.02 & 62.97 & 6.42 & 36.69 & 10.72 & 61.26 & 7.04 & 40.23 \\
\hline 8 & 8.7 & 49.71 & 8.9 & 50.86 & 7.59 & 43.37 & 9.34 & 53.37 \\
\hline 12 & 6.02 & 34.40 & 11.80 & 67.43 & 6.58 & 37.60 & 11.31 & 64.63 \\
\hline 16 & 3.5 & 20.00 & 14.25 & 81.43 & 5.25 & 30.00 & 12.32 & 70.40 \\
\hline 20 & 2.2 & 12.57 & 15.48 & 88.46 & 3.55 & 20.29 & 13.88 & 79.31 \\
\hline 24 & 1.6 & 9.14 & 16.13 & 92.17 & 3.02 & 17.26 & 14.36 & 82.06 \\
\hline 28 & 0.7 & 4.00 & 16.98 & 97.03 & 1.74 & 9.94 & 16.00 & 91.43 \\
\hline 32 & 0.02 & 0.11 & 17.42 & 99.54 & 1.26 & 7.20 & 16.36 & 93.49 \\
\hline 36 & $\mathrm{ND}^{+}$ & $\mathrm{ND}^{+}$ & $\mathrm{ND}^{+}$ & $\mathrm{ND}^{+}$ & 0.71 & 4.06 & 16.78 & 95.89 \\
\hline
\end{tabular}

* Average of three determinations calculated according to the calibration range obtained for each compound in its pure form.

+ ND Not determined.

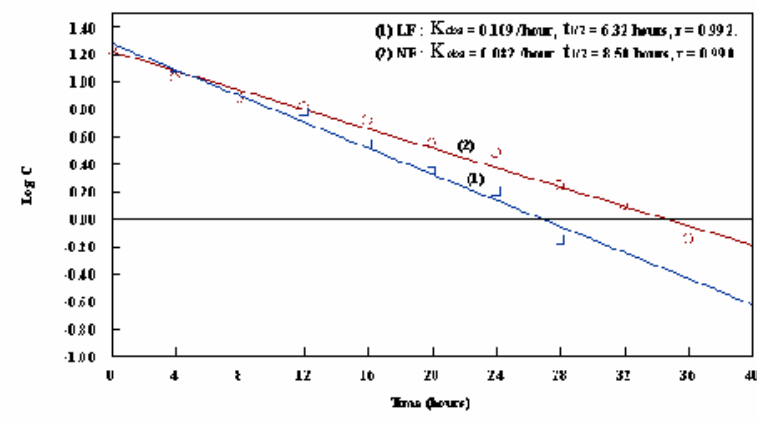

Fig. 3: The linear plot of $\log C$ versus time (hours) for the degradation of LF and $\mathrm{NF}$ upon heating at $150^{\circ}$ in $2 \mathrm{M} \mathrm{HCl}$ solutions.

\section{Conclusion}

The individual components of several prepared mixtures and the rate of degradation of some fluoroquinolone derivatives were simultaneously determined using spectrophotometric measurements together with CLS multivariate calibration analysis. The good recoveries obtained in all cases as well as the reliable results for the rates of degradation that agree well with the reports and analysis with other methods proved that, the proposed method could be applied efficiently for determination of pure fluoroquinolones, their decarboxylation derivatives as well as the degradation rates and determination of other kinetic parameters in case of marked spectral overlapping and/or presence of serious interferences with other methods such as HPLC.

\section{REFERENCES}

1- H. Kalant and W. H. E. Roschlau, Principle of Medical Pharmacology, $6^{\text {th }}$ Ed., New York, USA (1998).

2- B. G. Katzung, Basic \& Clinical Pharmacology, $8^{\text {th }}$ Ed., McGraw-Hill, New York, USA (2001).

3- E. M. Wolff, Burger Medicinal Chemistry, Part II, John Wiley and Sons, New York, USA (1996).

4- K. Parfitt, Martindal, The Complete Drug Reference, $32^{\text {nd }}$ Ed., Pharmaceutical Press, USA (1999).

5- J. N. Delgado and W. A. Remers, Wilson and Gisvold's Textbook of Organic Medicinal and Pharmaceutical Chemistry, $10^{\text {th }}$ Ed., J. B. Lippincott Company, London and New York (1998).

6- A. Nangia, L. Frederick and T. H.Cheung, Drug Dev. \& Ind. Pharm., 17, 681 (1991). 
7- M. E. Hidalgo, C. Pessoa, E. Fernandez and A. M. Cardenas, J. Photochem. Photobio. A. Chem., 73, 135 (1993).

8- S. Boettcher, H. von Baum, T. HoppeTichy, C. Benz, H. G. Sonntag, J. Pharm. Biomed. Anal., 25, 197 (2001).

9- W. V. Caulteld and J. T. Stewart, J. Liq. Chromatogr. \& Rel. Technol., 25, 1791 (2002).

10- U. Neckel, C. Joukhadar, M. Frossard, W. Jaeger, M. Mueller and B. X. Mayer, Anal. Chim. Acta., 463, 199 (2002).

11- F. A. Wong, S. J. Juzwin and S. C. Flor; J. Pharm. Biomed. Anal., 15, 765 (1997).

12- W. Ci, Y. Chai, L. L. Liu, C. Yin and Y. T. Wu, Yaowu Fenxi Zazhi, 20, 240 (2000).

13- S. Z. El-Khateeb, S. A. Abdel Razek and M. M. Amer, J. Pharm. Biomed. Anal., 17, 829 (1998).

14- H. Dong-sun, K. Hee-Jung, P. Kun and C. Won-Bong, J. Pharm. Biomed. Anal., 12, 157 (1994).

15- M. Stankov, D. Stankov, Z. Milicevic, D. Veselinovic and P. Djurd-jevic, Spectrosc. Lett., 26, 1709 (1993).

16- J. A. Ocana Gonzalez, M. Callejon Mochon and F. J. Barragan de la Rosa, Talanta, 52, 1149 (2000).

17- J. A. Ocana, M. Callejon and F. J. Barragan, Analyst, 125, 1851 (2000).

18- Q. J. Gong, J. L. Qiao, L. M. Du, C. Dong and W. J. Jin, Talanta, 53, 59 (2000).

19- M. Sakai, A. Hara, S. Anjo and M. Nakamura, J. Pharm. Biomed. Anal., 18, 1057 (1998).

20- X. L. Wang, S. M. Zhang, W. W. Zhang and W. S. Wu, Fenxi Huaxue, 23, 1189 (1995).

21- Z. Atkosar, G. Altiokka and B. Ergun, Pharmazie, 57, 587 (2002).
22- A. Radi and Z. El-Sherif, Talanta, 58, 319 (2002).

23- United States Pharmacopeia 24 and NF 19, American Pharmace-utical Association, Washington, DC, 2000, pp. 1203-4.

24- British Pharmacopoeia, Her Majesty's Stationary Office, London, UK, 1999, p. 922.

25- G. N. Singh, Pharmazie, 43, 134 (1988).

26- L. H. Hoppe, C. E. Johnson, E. M. Fontana and J. M. Meram, ASHP Midyear-Clinical Meeting, 33 (1998) 248R.

27- Y. Li, S. Don, Y. Zhu, J. Yang and L. Yang, Zhongguo Yaoke Daxue Xuebao, 24, 33 (1993).

28- N. R. Draper and H. Smith, Applied Regression Analysis, $2^{\text {nd }}$ Ed., John Wiley \& Sons, New York, 1981, pp. 70-140.

29- H. Martens and T. Naes, Multivariate Calibration, John Wiley \& Sons, New York (1989).

30- K. Mahalanabis and D. Basu, Analyst, 114, 1311 (1989).

31- C. Demir and R. G. Brereton, Analyst, 123, 181 (1998).

32- H. C. Goicoechea and A. C. Olivieri, Talanta, 47, 103 (1998).

33- N. Capitan-Vallvey, M. Kalil, A. Deheidel, I. de Orbe and R. Avidad, Analyst, 124, 49 (1999).

34- M. J. Benito, M. C. Ortiz, M. S. Sanchez, L. A. Sarabia and M. Iniguez, Analyst, 124, 547 (1999).

35- J. A. Hernandez-Arteseros, R. Compano, R. Ferrer and M. D. Prat, Analyst, 125, 1155 (2000). 